\title{
An index of specific behaviors in the moral domain
}

\author{
ROGER A. CHADWICK, GREGG BROMGARD, IRINA BROMGARD, and DAVID TRAFIMOW \\ New Mexico State University, Las Cruces, New Mexico
}

\begin{abstract}
Studies on attribution in the moral domain often involve the use of specific behavior examples. To make valid comparisons across trait dimensions (such as honesty and friendliness), it is important to equate the intensities of the specific behaviors used. Pretesting specific behaviors can be a costly effort, but it is often necessary for research in social psychology. Our study provides a rich source of such pretested behaviors. Positive and negative examples of behaviors in the categories of honesty, loyalty, friendliness, charitableness, and cooperativeness were solicited from participants and then rated on the relevant trait dimension by an independent group. The result is data representing rankings, raw scores, and $z$-scores in an index of 500 behaviors across 10 trait categories that can be used by researchers to study moral and immoral behaviors. The full index of behaviors is available at www .psychonomic.org/archive/.
\end{abstract}

Behavioral stimuli that pertain to specific moral dimensions are used in much research in social psychology. Researchers in person memory, attribution, and stereotyping (to name just a few topics) often use specific behaviors as stimuli and assume that these behaviors are related to broader trait dimensions (Brown, Trafimow, \& Gregory, 2005; Reeder \& Brewer, 1979; Reeder \& Coovert, 1986; Rothbart \& Park, 1986; Trafimow, 1998; Trafimow \& Schneider, 1994; Vonk, 1993; Vonk \& Van Knippenberg, 1994). However, this is just an assumption, and it is not necessarily clear whether or not it is actually true or how strong the specific trait-behavior relations may be. Because knowledge of specific trait-behavior relations is a prerequisite for the validity of so much research in person memory, attribution, stereotyping, and other areas, our goal was to provide a large index of ratings of specific trait-behavior relations that would satisfy this requirement.

In addition, it is sometimes necessary to compare various behaviors on the topic of interest across trait categories. Trait attribution is clearly trait dependent (Biernat $\& \mathrm{Ma}, 2005)$; for example, it is easier to disconfirm that a person is honest than to disconfirm that a person is friendly, because the observance of a single dishonest behavior carries more attributional weight than does the observance of one unfriendly act (Trafimow, Bromgard, Finlay, \& Ketelaar, 2005). An assortment of theoretical constructs has been developed in attempts to explain and understand these differences. However, it is often difficult to test these theoretical constructs because of the necessity to make comparisons across trait dimensions. In making

\footnotetext{
We acknowledge Grace Anne Carew and Orlando Gonzalez, undergraduate students at New Mexico State University, for their valuable assistance on this project. Correspondence concerning this article should be addressed to R. A. Chadwick, Department of Psychology, MSC 3452, New Mexico State University, P.O. Box 30001, Las Cruces, NM $88003-$ 8001 (e-mail: rchadwic@nmsu.edu).
}

these comparisons, differences in the intensities of the specific behaviors along their respective trait dimensions must be controlled. Although there is an increasing trend among attribution researchers to test theories that specify different attributional processes for different trait dimensions (Birnbaum, 1972, 1973; Klein, 1991; Lupfer, Weeks, \& Dupuis, 2000; Peeters, 1971; Reeder \& Brewer, 1979; Rothbart \& Park, 1986; Skowronski \& Carlston, 1987; Trafimow \& Schneider, 1994; Trafimow \& Trafimow, 1999; Vonk, 1993; Vonk \& Van Knippenberg, 1994), these researchers all face the necessity to compare trait-behavior relations across different trait dimensions. Cross-categorical comparisons of this sort are difficult to interpret properly, and careful analytical methods must be employed when doing so. If generalizations are to be valid, a variety of specific examples must be used and a means of assuring equivalence across categories employed.

Assuring equivalent intensity of items across trait dimensions is not as straightforward as it might at first appear. The method used to determine equivalence across trait dimensions depends on the specific needs of the research and the assumptions about the frequency distributions of the sample items obtained in each trait dimension. When a limited sample of behaviors drawn from a potentially infinite population of trait-related behaviors is considered, it is not clear what is actually included in the potential set of cases that could have appeared in the samples with equal probability (see Hays \& Winkler, 1970, p. 299). It is reasonable to assume that the actual distributions of items in different trait dimensions would differ in terms of normality and central tendency, and the implications of these differences must be taken into account when one makes comparisons across trait dimensions.

Two candidate methods for comparison are (1) use of the raw mean scores of the items and (2) use of standardized $z$-scores. Each of these methods has its merits and 
pitfalls, and in most circumstances results (i.e., items selected as equivalent and therefore comparable) will differ depending on the method chosen. If the same measurement scale is used for all trait dimensions, the use of mean scores for comparison is reasonable. To choose behaviors that pertain to different trait dimensions but are of equivalent intensities, it is sufficient to choose those that have equivalent raw mean scores. Unfortunately, this method is vulnerable to several potential problems. The main problem is the necessity to assume that participants are using equivalent scales, or using the same scale in an equivalent way, across the different trait dimensions - the proverbial problem of comparing apples and oranges. In the attribution area, at least, this assumption is particularly problematic (see, e.g., Reeder \& Brewer, 1979; Rothbart \& Parks, 1986; Trafimow \& Schneider, 1994). This is because attribution theorists often postulate that there are different trait attribution processes for different trait dimensions and, therefore, assuming that the scales will be used in the same way is a risky proposition. Second, raw mean scores do not provide any quantitative information about the relations between the items. Although these scales are certainly ordinal and may reflect some interval properties, it is not clear, for example, whether or not an item with a mean raw score of 2.0 on friendliness is actually twice as friendly as an item with a mean raw score of 1.0. This is particularly problematic if the population from which the sample was drawn is not normally distributed, and we have no a priori reason to believe that this would be the case.

To solve the problem of comparing behaviors that pertain to different trait dimensions (in other words, to allow a comparison of "apples and oranges"), statisticians recommend converting raw scores to $z$-scores (J. Cohen \& P. Cohen, 1983, pp. 31-34; R. J. Cohen \& Swerdlik, 1999, pp. 110-111; Gravetter \& Wallnau, 2000, p. 160). A $z$ score conversion is used when one wishes to emphasize the status of a score within a distribution (Hays, 1973, p. 252). Standardization is achieved by subtracting the mean of the sample from the raw score and dividing by the $S D$ of the sample. Because $z$-scores give the number of $S D$ s by which a $z$-score deviates from its sample mean, it is possible to compare scores from different samples in terms of within-sample deviations even if the samples come from populations with very different or nonnormal distributions. Thorndike and Hagen (1969) provided a classic example of how this procedure is used to make comparisons across categories that are very different from each other. Thorndike and Hagen, in discussing statistical methods concerning comparisons of math ability and language ability, needed to make comparisons of how good people who took a math test were at math versus how good people who took a language test were at that language. By using $z$-score conversion, these researchers were able to state exactly how much each person who took the math test deviated from the math sample mean, and exactly how much each person who took the language test deviated from the language sample mean. Thus, they were able to state, for example, that people who took different tests, but who obtained the same $z$-score, were equiva- lent in their abilities despite the fact that the math and language tests differed in a large number of ways (e.g., different contents, different means, different $S D$ s). Analogically, if two behaviors pertaining to different trait dimensions (e.g., honesty and friendliness) have the same $z$ score, this means that each behavior deviates by the same number of $S D$ s from the sample mean of its respective trait dimension; the two behaviors are equivalent relative to their respective trait dimensions (e.g., the honest behavior is as honest as the friendly behavior is friendly). This is a key point, for if we consider a simple example of two distributions of trait-relevant behaviors that differ in terms of central tendency, and we wish to compare typical behaviors from each trait dimension, the use of equivalent raw scores will not reflect the central tendencies of both distributions. In contrast, the use of $z$-scores of 0 , representing the mean of each respective distribution, will reflect the central tendencies.

In addition to solving the "apples and oranges" problem, $z$-score conversion provides standardized scores with a mean of 0 and an $S D$ of 1 regardless of the characteristics of the population distribution (Gravetter \& Wallnau, 2000). For example, although a raw score of 2 is not necessarily twice as large as a raw score of 1 , it is the case that a $z$-score of 2 (2 $S D$ s from the mean) is twice as large as a $z$-score of 1 ( $1 S D$ from the mean). Although many researchers are not extremely familiar with $z$-scores, they are familiar with Pearson correlation coefficients, which entail $z$-score conversion in a slightly disguised form. Specifically, a Pearson correlation coefficient is a standardized covariance; it is the covariance between two variables after all of the raw scores have been converted to $z$-scores. ${ }^{1}$

Despite the advantages of $z$-scores, they do have one important disadvantage. Specifically, their validities are limited by the validities of the samples from which they are constructed. If the samples do not accurately reflect the characteristics of the populations from which they were selected, then, although the $z$-scores computed on the basis of sample characteristics will accurately give the placement of each item relative to other items in the sample, they may not give the placement of each item relative to other items in the population. For this reason, it is wise to have large samples. (At least 30 items per sample is a general rule of thumb.) With all of the foregoing issues in mind, the goal of our research was to provide an index of ratings in terms of rankings, mean scores, and standardized $z$-scores for a relatively large range of behaviors (50) for each of 10 traits that reflect a variety of moral dimensions of interest. The result is a list of 500 behaviors in the moral domain that can be used across research paradigms to (1) eliminate confounds and the need for repeated, costly pretesting and (2) provide greater cohesion in the social psychology literature.

\section{METHOD}

\section{Solicitation of Behaviors}

Behaviors were solicited in an unbiased manner that we felt would result in a sample distribution that accurately reflected the characteristics of the population. Twenty undergraduate students at New 


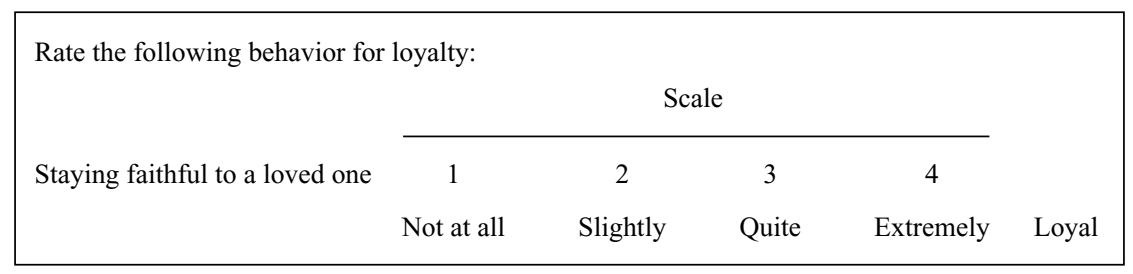

Figure 1. Sample behavior item for the category "loyalty," with instruction to the participants and rating scale.

Mexico State University were instructed to provide five specific examples of behaviors in each of 10 categories. The categories were honesty, dishonesty, loyalty, disloyalty, charitableness, uncharitableness, friendliness, unfriendliness, cooperativeness, and uncooperativeness. Thus, a maximum of 1,000 (20 participants $\times 5$ examples $\times 10$ categories) line items could be produced, although a few items were left blank because some participants failed to come up with the requisite number of examples in particular categories.

\section{Selection of Behaviors}

Duplicate and irrelevant behaviors were deleted from the sample. The criteria for relevance were that the behavior had to fit the category (as determined by a consensus of 3 researchers) and be specific enough to use in a scenario. Items such as "stealing" were dropped from the sample for lack of specificity. The remaining behaviors were randomly sorted, and 50 were randomly selected from each category, resulting in a total of 500 behaviors. Items were corrected for grammatical and spelling errors and made gender neutral where possible (e.g., husband or wife was changed to spouse). This list was then prepared for rating by an independent group of participants.

\section{Procedure}

Sixty male and female undergraduate students (mean age $=$ 20.7 years) at New Mexico State University rated the list of 500 behavior items. To control for order effects, the categories were counterbalanced, the items within each category were randomized, and half of the participants responded to the items in forward order and the other half in reverse order. For each specific behavior item, the participants provided a rating for the relevant trait on a 4-point scale (on which $1=$ not at all, $2=$ slightly, $3=$ quite, and $4=e x-$ tremely). An example of a typical item is provided in Figure 1.

\section{RESULTS}

The data from all 60 participants were aggregated, and the mean and $S D$ for each item were calculated. Using these data, the trait category means and $S D$ s of items within each category were calculated. Table 1 contains a summary of category means and $S D$ s, along with statistics describing the shapes and normal fits of the distributions. When behaviors within a particular category are compared, a difference between raw ratings of approximately 0.2 represents a statistically significant difference $(\alpha=.05$; exact statistical significance differences depend on the particular items being compared). The means and $S D$ s of within-category items were then used to calculate a standardized $z$-score for each item $[z=(x-M) / S D]$ such that the mean $z$-score in each category is 0 and the $S D$ is 1 . Thus, behaviors that are rated as strong with regard to the particular trait have more positive $z$-scores, and relatively weak behaviors are reflected in more negative $z$ scores. The resulting index, including rankings, $z$-scores, mean scores, and $S D$ s (of raw ratings by participants), is provided in its entirety in the Archived Materials and in condensed form in Table 2. Items within each category are listed in order of descending $z$-score, with the behaviors most strongly associated with the trait listed first.

The categories chosen include both positive (e.g., honesty, friendliness) and negative (e.g., dishonesty, unfriendliness) moral dimensions. This could be somewhat confusing; therefore, note that for all categories, high mean scores (positive $z$-scores) represent behaviors that are considered to be strong exemplars of the particular moral trait, whereas low mean scores (negative $z$-scores) represent behaviors that are considered to be weak exemplars. For example, in the negative behavioral category of dishonesty, more positive scores represent more dishonesty and more negative scores represent less dishon-

Table 1

Trait Category Statistics

\begin{tabular}{lcccrrc}
\hline \multicolumn{1}{c}{ Trait $(n=50)$} & $M$ & $M d n$ & $S D$ & Skewness & Kurtosis & Shapiro-Wilk $W$ \\
\hline Charitability & 2.997 & 2.935 & 0.363 & -0.034 & -0.184 & .977 \\
Cooperativeness & 2.985 & 3.000 & 0.176 & 0.208 & -0.403 & .982 \\
Dishonesty & 3.181 & 3.140 & 0.441 & -0.414 & -0.783 & $.948^{*}$ \\
Disloyalty & 3.099 & 3.210 & 0.494 & -1.002 & 1.247 & $.937^{*}$ \\
Friendliness & 3.024 & 2.975 & 0.247 & 0.240 & -0.796 & .966 \\
Honesty & 3.340 & 3.335 & 0.216 & -0.269 & 0.367 & .984 \\
Loyalty & 3.284 & 3.300 & 0.283 & -1.070 & 1.928 & $.938^{*}$ \\
Uncharitability & 2.831 & 2.905 & 0.492 & -0.403 & -0.438 & .972 \\
Uncooperativeness & 2.997 & 3.020 & 0.359 & -0.675 & 0.303 & .960 \\
Unfriendliness & 3.009 & 3.070 & 0.466 & -1.147 & 1.886 & $.925^{*}$ \\
$\quad$ Total $(N=500)$ & 3.07 & 3.110 & 0.396 & -0.760 & 1.104 & $\mathrm{n} / \mathrm{a}$ \\
\hline
\end{tabular}

Note-Responses were made on a scale from 1 (not at all) to 4 (extremely) [trait]. The standard error of skewness for all trait categories is 0.337 . The standard error of kurtosis for all trait categories is $0.662 .{ }^{*}$ The distribution differs significantly $(p<.05)$ from a normal distribution. 
Table 2

Index of Behaviors in the Moral Domain (Condensed Version)

\begin{tabular}{|c|c|c|c|c|c|}
\hline Category & Rank & Behavior & $M$ & $S D$ & $z$ \\
\hline \multirow[t]{5}{*}{ Charitability } & 3 & helping build a home for the needy & 3.60 & 0.56 & 1.659 \\
\hline & 14 & donating blood & 3.27 & 0.84 & 0.751 \\
\hline & 22 & lending a hand to a person with a flat tire & 3.03 & 0.69 & 0.090 \\
\hline & 40 & $\begin{array}{l}\text { helping a friend who is in need of laundry money by giving them some } \\
\text { money }\end{array}$ & 2.77 & 0.79 & -0.625 \\
\hline & 47 & buying newspapers from the person on the street & 2.38 & 0.90 & -1.698 \\
\hline \multirow[t]{5}{*}{ Cooperativeness } & 3 & $\begin{array}{l}\text { accepting that you were wrong and taking actions that were previously } \\
\text { opposite to your beliefs }\end{array}$ & 3.27 & 0.76 & 1.614 \\
\hline & 12 & agreeing to take an unplanned detour that the group wants to see & 3.12 & 0.78 & 0.766 \\
\hline & 22 & going with friends to a club that doesn't play your type of music & 3.02 & 0.72 & 0.200 \\
\hline & 38 & helping your mom/dad bring in the groceries & 2.85 & 0.71 & -0.761 \\
\hline & 48 & paying attention in class & 2.72 & 0.80 & -1.497 \\
\hline \multirow[t]{5}{*}{ Dishonesty } & 1 & cheating on wife/husband/girlfriend/boyfriend & 3.85 & 0.52 & 1.518 \\
\hline & 17 & borrowing/taking money from a roommate without asking & 3.50 & 0.75 & 0.724 \\
\hline & 25 & smoking weed and telling your mom you don't & 3.15 & 0.82 & -0.070 \\
\hline & 38 & accepting more than the correct change when making a purchase & 2.85 & 0.88 & -0.751 \\
\hline & 48 & lying about your age to get into a nightclub & 2.47 & 0.96 & -1.614 \\
\hline \multirow[t]{5}{*}{ Disloyalty } & 1 & having sex with a friend's significant other & 3.85 & 0.61 & 1.520 \\
\hline & 12 & badmouthing a good friend behind their back & 3.47 & 0.65 & 0.751 \\
\hline & 29 & if you tell a secret someone told you & 3.05 & 0.72 & -0.099 \\
\hline & 41 & taking your friend's ex's side when they break up & 2.73 & 0.97 & -0.747 \\
\hline & 46 & saying bad things about your place of employment & 2.38 & 0.83 & -1.455 \\
\hline \multirow[t]{5}{*}{ Friendliness } & 3 & helping a stranger pick up stuff they have dropped & 3.43 & 0.62 & 1.642 \\
\hline & 13 & helping someone find a lost dog & 3.18 & 0.81 & 0.632 \\
\hline & 24 & giving a compliment & 3.00 & 0.71 & -0.096 \\
\hline & 38 & speaking to the person behind the register at a gas station & 2.83 & 0.72 & -0.784 \\
\hline & 47 & waving back when a friend waves & 2.67 & 0.80 & -1.430 \\
\hline \multirow[t]{5}{*}{ Honesty } & 3 & not cheating on a test even if you have the answers in front of you & 3.65 & 0.68 & 1.436 \\
\hline & 13 & correcting a cashier when they give you too much change & 3.48 & 0.79 & 0.648 \\
\hline & 25 & returning jewelry a friend lent you, but doesn't remember you have it & 3.35 & 0.76 & 0.045 \\
\hline & 43 & when you buy something for a friend, giving them their change & 3.17 & 0.78 & -0.790 \\
\hline & 46 & telling your friend that an outfit is not becoming of her & 3.05 & 0.77 & -1.347 \\
\hline \multirow[t]{5}{*}{ Loyalty } & 3 & staying faithful to a loved one & 3.68 & 0.50 & 1.396 \\
\hline & 14 & standing up for a friend when they are being teased or harassed & 3.47 & 0.60 & 0.655 \\
\hline & 26 & turning down a date with your best friend's "ex" & 3.30 & 0.74 & 0.055 \\
\hline & 41 & maintaining a job when a salary increase is available somewhere else & 3.10 & 0.88 & -0.651 \\
\hline & 48 & keeping sacred induction rituals of your sorority or fraternity a secret & 2.82 & 1.00 & -1.639 \\
\hline \multirow[t]{5}{*}{ Uncharitability } & 2 & having millions of dollars and not helping one person in need of something & 3.55 & 0.75 & 1.461 \\
\hline & 13 & not giving tips for any kind of service & 3.15 & 0.73 & 0.648 \\
\hline & 26 & not giving a ride to a friend who needs it & 2.88 & 0.74 & 0.100 \\
\hline & 37 & eating out alone because you know your friend is broke & 2.45 & 0.96 & -0.774 \\
\hline & 48 & not wanting anyone over for dinner & 2.02 & 0.87 & -1.648 \\
\hline \multirow[t]{5}{*}{ Uncooperativeness } & 1 & not pulling over for an ambulance that is trying to pass you & 3.63 & 0.55 & 1.762 \\
\hline & 14 & continuing to ask someone on a date when they have asked you not to & 3.25 & 0.88 & 0.705 \\
\hline & 28 & skipping scheduled appointments & 2.98 & 0.77 & -0.046 \\
\hline & 39 & ditching one friend because another has more plans that night & 2.78 & 0.90 & -0.602 \\
\hline & 48 & going to the place you want to eat all the time & 2.42 & 0.91 & -1.604 \\
\hline \multirow[t]{5}{*}{ Unfriendliness } & 2 & yelling at the store clerk for no good reason & 3.62 & 0.74 & 1.311 \\
\hline & 14 & giving someone dirty looks because of their clothing, hair, etc. & 3.35 & 0.78 & 0.731 \\
\hline & 30 & providing customer service without a "hello," "thank you," or "goodbye" & 3.00 & 0.86 & -0.020 \\
\hline & 40 & not holding a door for someone who is following you into a building & 2.68 & 0.77 & -0.707 \\
\hline & 46 & not saying "hello" to old teachers or professors & 2.37 & 0.80 & -1.373 \\
\hline
\end{tabular}

Note- $M$, mean raw score on a scale from 1 (not at all) to 4 (extremely) [trait]; $S D$, standard deviation of raw scores for the item $(N=60)$; $z$, within-category standard $z$-score. Rank refers to an item's position in the 50 -item behavioral category for which it was rated.

esty. For the positive behavioral category of friendliness, more positive scores represent more friendliness and more negative scores represent less friendliness.

\section{DISCUSSION}

The large sample of 50 behaviors in each category gives this behavior index the potential to be extremely useful, with an unlimited number of possible applications in a variety of areas of social psychology. In general, published indices such as the one we present in the Archived Materials enable researchers to gain several advantages. In the first place, researchers can avoid time-consuming and costly pretesting of experimental materials. Second, our index is likely to be much larger than those that would be created in the course of routinely small pilot studies. 
Third, the widespread use of materials from an index of the sort presented here should allow for greater comparability across studies, because many studies would be using the same materials, or at least materials with known relations derived from the same index. Finally, having a large published index should help mitigate what we believe is a large problem in social psychology: the fact that much research is based on hastily performed pilot studies of dubious quality.

As an example, Fuhrman, Bodenhausen, and Lichtenstein (1989) provided an index with normative ratings of 400 behavioral items that has been subsequently used by other researchers (e.g., Malle \& Bennett, 1998). In contrast with our index, that of Fuhrman et al. provides rankings instead of $z$-scores (one could, of course, calculate $z$-scores from these data, since mean ratings are provided). The inclusion of $z$-scores in our data provides information beyond simple ranking regarding the relations among the behaviors within a given trait category. Our data, sorted on the basis of $z$-scores, provide not only ranking information but, more importantly, quantitative information regarding actual differences in ratings, so that these scores can be treated as interval data for most analysis purposes. By incorporating information about the entire distribution of items, $z$-scores can be more informative than mean raw scores alone.

The decision to use rankings, mean scores, or $z$-scores depends on the specific requirements of the research questions being asked and the researcher's willingness to accept certain assumptions. If one needs only assume that the data are ordinal, then it makes sense to use rankings. Mean ratings may be used if one assumes that they provide an absolute scale on which items pertaining to different traits can be equated, or if one is simply interested in equitable intensities of items along their respective dimensional scales. Standardized $z$-scores can be used to match items on the basis of their positions in comparison with those of other items pertaining to the same trait. Perhaps the best choice is one that is conservative with regard to the specific theoretical issues being tested. Some research areas that could benefit from the use of these data are discussed next.

\section{Attribution}

Researchers in this field are well aware that trait attribution is not a simple process (Rothbart \& Park, 1986) but has many dependencies and apparently peculiar attribution rules for different traits (Skowronski \& Carlston, 1987; Trafimow \& Schneider, 1994). Work is ongoing in the area of comparisons of attribution responses for behaviors categorized under various theoretically constructed types, or schemata, such as partially or hierarchically restrictive schemata (Reeder \& Brewer, 1979) and Kant's (1797/1991) philosophical and rationally based distinctions of perfect and imperfect duties (Trafimow et al., 2005; Trafimow \& Trafimow, 1999). These kinds of investigations often depend on comparing the effects of behaviors in different categories to reveal possible differences in attributions such as negativity effects (see, e.g.,
Aloise, 1993; Birnbaum, 1973; Kanouse \& Hanson, 1965; Rothbart \& Park, 1986). But to do this research properly, we need to know, for example, whether or not the dishonest and honest behaviors used in an experiment are really equal on their respective dimensions. Our study provides both positive and negative behaviors that are readily comparable and, therefore, equitable.

\section{Stereotyping}

One approach to understanding mechanisms of stereotyping centers on traits as the unit of analysis (Schaller, Conway, \& Tanchuk, 2002). For example, the confirmability or communicability of a trait can affect the degree of stereotyping (Schaller et al., 2002, p. 862). If studies reveal, for instance, that a particular minority group is more easily confirmed as having particular negative or positive traits on the basis of the observance of particular negative or positive behaviors, the behaviors used must be known to be equivalent in order for the results to be trusted.

\section{Person Memory and the Incongruity Effect}

In assessing the processes and nature of mental representations of persons, impression formation, and person memory, a typical paradigm requires participants to form impressions of target persons on the basis of specific behavior observations (Srull \& Wyer, 1989). Targets are often characterized by certain trait valences, and the effects of congruent and incongruent behaviors are analyzed (Trafimow \& Finlay, 2001). Although there is much empirical evidence to support the proposition that incongruent information undergoes more processing than congruent information (see, e.g., Bargh \& Thein, 1985; Srull, 1981; Srull, Lichtenstein, \& Rothbart, 1985), this result is not without complications (Trafimow \& Finlay, 2001). Determinations made without particular care to equate stimulus behaviors that are considered congruent with those that are considered incongruent are likely to be flawed.

\section{Moral Theory}

Finally, moral theorists might be interested in theoretical reasons for the relative strength of various items. Just why is it that some behaviors are considered more dishonest or disloyal than others? Although it is intuitive that some behavior is good and some bad, it is not intuitive why particular behaviors might be considered better or worse than others, and it is not clear why we place particular value judgments on particular acts. These data provide a starting point for new theories in this area, or at least a body of evidence that may constrain current theories, since these theories should not contradict our data. In short, it is our hope that this listing will prove useful in diverse areas of social psychology.

\section{REFERENCES}

Aloise, P. A. (1993). Trait confirmation and disconfirmation: The development of attribution biases. Journal of Experimental Child Psychology, 55, 177-193.

BARgh, J. A., \& TheIn, R. D. (1985). Individual construct accessibility, 
person memory, and the recall-judgment link: The case of information overload. Journal of Personality \& Social Psychology, 49, 1129-1146.

Biernat, M., \& MA, J. E. (2005). Stereotypes and the confirmability of trait concepts. Personality \& Social Psychology Bulletin, 31, 483-495.

Birnbaum, M. H. (1972). Morality judgments: Tests of an averaging model. Journal of Experimental Psychology, 93, 35-42.

Birnbaum, M. H. (1973). Morality judgment: Test of an averaging model with differential weights. Journal of Experimental Psychology, 99, 395-399.

Brown, J., Trafimow, D., \& Gregory, W. L. (2005). The generality of negative hierarchically restrictive behaviours. British Journal of Social Psychology, 44, 3-13.

Cohen, J., \& Cohen, P. (1983). Bivariate correlation and regression. In J. Cohen \& P. Cohen (Eds.), Applied multiple regression/correlation analysis for the behavioral sciences (2nd ed., pp. 25-78). Hillsdale, NJ: Erlbaum.

Cohen, R. J., \& Swerdlik, M. E. (1999). Psychological testing and assessment: An introduction to tests and measurement (4th ed.). Mayfield, CA: Mountain View.

Fuhrman, R. W., Bodenhausen, G. V., \& Lichtenstein, M. (1989). On the trait implications of social behaviors: Kindness, intelligence, goodness, and normality ratings for 400 behavior statements. Behavior Research Methods, Instruments, \& Computers, 21, 587-597.

Gravetter, F. J., \& Wallnau, L. B. (2000). Statistics for the behavioral sciences. Belmont, CA: Wadsworth.

Hays, W. L. (1973). Statistics for the social sciences (2nd ed.). New York: Holt, Rinehart \& Winston.

Hays, W. L., \& WinkLer, R. L. (1970). Statistics, probability, inference, and decision. New York: Holt, Rinehart \& Winston.

Kanouse, D. E., \& Hanson, K. E. (1965). Negativity in evaluations. In E. E. Jones et al. (Eds.), Attribution: Perceiving the causes of behavior (pp. 47-62). Morristown, NJ: General Learning Press.

KAnT, I. (1991). The metaphysics of morals (M. Gregor, Trans.). Cambridge: Cambridge University Press. (Original work published 1797)

KLEIN, J. G. (1991). Negativity effects in impression formation: A test in the political arena. Personality \& Social Psychology Bulletin, 17 412-418.

Lee, M. D., \& Wagenmakers, E.-J. (2005). Bayesian statistical inference in psychology: Comment on Trafimow (2003). Psychological Review, 112, 662-668

Lupfer, M. B., Weeks, M., \& Dupuis, S. (2000). How pervasive is the negativity bias in judgments based on character appraisal? Personality \& Social Psychology Bulletin, 26, 1353-1366.

Malle, B. F., \& Bennett, R. E. (1998, August). People's praise and blame for intentions and actions: Implications of the folk concept of intentionality. Paper presented at the 106th annual convention of the American Psychological Association, San Francisco.

Peeters, G. (1971). The positive-negative asymmetry: On cognitive consistency and positivity bias. European Journal of Social Psychology, 1, 455-474.

ReEder, G. D., \& Brewer, M. B. (1979). A schematic model of dispositional attribution in interpersonal perception. Psychological Review, 86, 61-79.

Reeder, G. D., \& Coovert, M. D. (1986). Revising an impression of morality. Social Cognition, 4, 1-17.

Rothbart, M., \& PARK, B. (1986). On the confirmability and disconfirmability of trait concepts. Journal of Personality \& Social Psychology, 50, 131-142.

Schaller, M., Conway, L. G., III, \& Tanchuk, T. L. (2002). Selective pressures on the once and future contents of ethnic stereotypes: Effects of the communicability of traits. Journal of Personality \& Social Psychology, 82, 861-877.

Skowronski, J. J., \& Carlston, D. E. (1987). Social judgment and social memory: The role of cue diagnosticity in negativity, positivity, and extremity biases. Journal of Personality \& Social Psychology, 52, 689-699.

SRUlL, T. K. (1981). Person memory: Some tests of associative storage and retrieval models. Journal of Experimental Psychology: Human Learning \& Memory, 7, 440-463.
Srull, T. K., Lichtenstein, M., \& Rothbart, M. (1985). Associative storage and retrieval processes in person memory. Journal of Experimental Psychology: Learning, Memory, \& Cognition, 11, 316-345.

SRULl, T. K., \& WYER, R. S., JR. (1989). Person memory and judgment. Psychological Review, 96, 58-83.

ThorNdike, R. L., \& HAGEN, E. (1969). Norms and units of measurement. In R. L. Thorndike \& E. Hagen (Eds.), Measurement and evaluation in psychology and education (3rd ed., p. 225). New York: Wiley.

Trafimow, D. (1998). Situation-specific effects in person memory. Personality \& Social Psychology Bulletin, 24, 314-321.

Trafimow, D. (2003). Hypothesis testing and theory evaluation at the boundaries: Surprising insights from Bayes's theorem. Psychological Review, 110, 526-535.

Trafimow, D. (2004). Problems with change in $R^{2}$ as applied to theory of reasoned action research. British Journal of Social Psychology, 43, 515-530.

Trafimow, D., Bromgard, I. K., Finlay, K. A., \& Ketelaar, T. (2005). The role of affect in determining the attributional weight of immoral behaviors. Personality \& Social Psychology Bulletin, 31, 935-948.

Trafimow, D., \& Finlay, K. A. (2001). An investigation of three models of multitrait representations. Personality \& Social Psychology Bulletin, 27, 226-241.

Trafimow, D., \& Schneider, D. J. (1994). The effects of behavioral, situational, and person information on different attribution judgments. Journal of Experimental Social Psychology, 30, 351-369.

Trafimow, D., \& Trafimow, S. (1999). Mapping perfect and imperfect duties onto hierarchically and partially restrictive trait dimensions. Personality \& Social Psychology Bulletin, 25, 686-695.

Vonk, R. (1993). The negativity effect in trait ratings and in open-ended descriptions of persons. Personality \& Social Psychology Bulletin, 19, 269-278.

Vonk, R., \& VAN KNIPPEnBERG, A. (1994). The sovereignty of negative inferences: Suspicion of ulterior motives does not reduce the negativity effect. Social Cognition, 12, 169-186.

\section{NOTE}

1. Note that although it is not necessary to assume normality to compute Pearson correlation coefficients, it is necessary to assume bivariate normality to perform the usual statistical tests of their significance (Hays, 1973, pp. 659-660). On the other hand, recent advances in statistics suggest that it may not be advisable to perform such statistical tests (see, e.g., Lee \& Wagenmakers, 2005; Trafimow, 2003, 2004).

\section{ARCHIVED MATERIALS}

The following materials associated with this article may be accessed through the Psychonomic Society's Norms, Stimuli, and Data archive, www.psychonomic.org/archive/.

To access these files, search the archive for this article using the journal name (Behavior Research Methods), the first author's name (Chadwick), and the publication year (2006).

FILE: Chadwick-BRM-2006.zip

DESCRIPTION: The compressed archive file contains four files:

ChadwickEtAl(2006)Table1.txt, containing trait category statistics.

ChadwickEtAl(2006)Table1.xls, containing the information above in Excel spreadsheet format.

ChadwickEtAl(2006)Table2.txt, containing the full index of behaviors in the moral domain.

ChadwickEtAl(2006)Table2.xls, containing the information above in Excel spreadsheet format.

AUTHOR's E-MAIL ADDREss: rchadwic@nmsu.edu.

AUthOR's Web SITE: web.nmsu.edu/ rchadwic/index.html.

(Manuscript received May 18, 2005; revision accepted for publication September 17, 2005.) 